\section{Supramolecular Microphase Separation in a Hydrogen-Bonded Liquid Crystalline Comb Copolymer in the Melt State}

\section{Chinedum O. Osuji, *, ${ }^{\dagger}$ Chi-Yang Chao, Christopher K. Ober, ${ }^{\dagger}$ and Edwin L. Thomas ${ }^{\S}$}

Division of Engineering and Applied Science, Harvard University, Cambridge Massachusetts 02138; Department of Materials Science and Engineering, Cornell University, Ithaca New York 14850; and Department of Materials Science and Engineering, Massachusetts Institute of Technology, Cambridge, Massachusetts 02139

Received November 29, 2005

Revised Manuscript Received March 24, 2006

Hydrogen bonding represents a versatile and convenient route to chemical diversity in natural and synthetic systems. It can be used to join various chemical species to one another to form products ranging from simple dimers to complex supramolecular moieties, some of which may be self-ordering. ${ }^{1,2}$ The use of hydrogen bonding to create liquid crystalline materials is an example of using molecular recognition to pursue prescribed molecular or supramolecular architectures for use in functional systems with self-assembled structures. ${ }^{3,4}$ Both low molecular weight and polymeric liquid crystals have been realized using hydrogen bonding, starting with the pioneering work of Kato and Frechet ${ }^{5}$ and continued by others in different systems. ${ }^{6-15}$ Ruokolainen et al. have used hydrogen bonding and charge transfer to complex aliphatic chains to homopolymers ${ }^{16-23}$ and block copolymers. ${ }^{24}$ Hydrogen bonding has also been used as a facile method for the preparation of LC block copolymers with novel thermooptic properties ${ }^{25}$ and that exhibit orientational switching of the microstructure under electric fields. ${ }^{26}$ The current work represents another instance of supramolecular engineering via hydrogen bonding.

Poly(acrylic acid) of molecular weight $5.2 \mathrm{~kg} / \mathrm{mol}$ and polydispersity 1.09 was used as received from Polymer Source. The custom-synthesized mesogen was based on an imidazole headgroup and a rigid biphenyl core, with 10- and 8-carbon aliphatic spacer and tail segments, respectively, as shown in Figure 1.

Samples were prepared by codissolving appropriate quantities of PAA and the mesogen in DMF at $2.5 \mathrm{wt} \%$ followed by slow solvent removal at $55^{\circ} \mathrm{C}$ to prevent mesogen crystallization and phase separation. The films produced were dried in a vacuum at room temperature for 72-96 $\mathrm{h}$ and used without further treatment. SAXS was performed using a rotating copper anode source $(\lambda=1.540 \AA$ ) and, primarily, a synchrotron source $(\lambda=1.307 \AA)$. DSC was conducted on a Perkin-Elmer DSC7 at a heating rate of $10{ }^{\circ} \mathrm{C} / \mathrm{min}$. FTIR was performed in reflection on films using a microscope objective for both illumination and collection of reflected radiation on a Nicolet instrument.

The mesogen forms a room temperature crystalline solid in the unbound state, with a single, sharp melting transition to a disordered liquid at $97{ }^{\circ} \mathrm{C}$. X-ray scattering revealed a layered structure of $35 \AA$ period in the small-angle regime and

\footnotetext{
Harvard University.

$\doteqdot$ Cornell University.

$\S$ Massachusetts Institute of Technology.

* To whom correspondence should be addressed. E-mail: cosuji@ deas.harvard.edu.
}

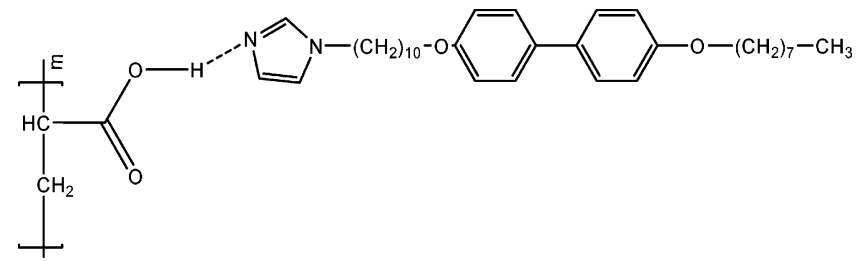

Figure 1. Structure of the PAA homopolymer and hydrogen-bonded imidazole mesogen.

characteristic peaks on the $3-5 \AA$ range in the wide-angle regime. The layer period was in good agreement with the calculated extended chain length of the molecule, $34 \AA$.

The presence of hydrogen bonding between the imidazole head of the mesogen and the hydroxy group of the acrylic acid repeat units was confirmed by FTIR - the appearance of a new, broad band centered on $2530 \mathrm{~cm}^{-1}$ was the primary indicator of strong imidazole-carboxylic acid hydrogen bonding. ${ }^{15}$ The intensity of the band was found to decrease as samples were heated above room temperature, with recovery of the room temperature absorption profile observed provided that the temperature did not exceed $180{ }^{\circ} \mathrm{C}$. Beyond this temperature, it is likely that some thermal degradation of the material results in a permanent loss of hydrogen-bonding capacity. The formation of a liquid crystalline complex is evidenced by the distinct thermal characteristics of sample films relative to either homopolymer or mesogen alone. For a stoichiometric (1.0 M) PAALC blend, there is a dominant melting transition at $86{ }^{\circ} \mathrm{C}$ followed by a smaller peak at $101{ }^{\circ} \mathrm{C}$. Strong optical activity coupled with a different mesophase layer period at room temperature as measured by X-ray diffraction confirms that the complex is liquid crystalline, homogeneous, and distinct from the precursor material in structure.

At room temperature, the substoichiometric $0.50 \mathrm{M}$ PAALC shows only one reflection in SAXS, at $21 \AA$. The evolution of structure in the material was studied by in-situ simultaneous 2-dimensional SAXS and WAXS between room temperature and $150{ }^{\circ} \mathrm{C}$. The sample was subjected to a heating rate of 10 ${ }^{\circ} \mathrm{C} / \mathrm{min}$ with films held at the pattern acquisition temperatures for $1 \mathrm{~min}$. The sample was first heated to the isotropic, disordered phase at $150{ }^{\circ} \mathrm{C}$ from room temperature, and then cooled to $105{ }^{\circ} \mathrm{C}$ before being reheated to $150{ }^{\circ} \mathrm{C}$ (second heating), cooled to $100{ }^{\circ} \mathrm{C}$ (second cooling), and again heated to $105^{\circ} \mathrm{C}$. The results of the experiment are given in Figure 2 .

On first heating above $100{ }^{\circ} \mathrm{C}$, there is a transition involving the disappearance of the room temperature $21 \AA$ reflection and the emergence of another LC type reflection (as judged by the intensity and breadth of the peak) in the $75 \AA$ range, $q=0.084$ $\AA^{-1}$. The $75 \AA \mathrm{LC}$ structure, present at $115^{\circ} \mathrm{C}$ and higher, may be accounted for by the mesogens adopting a loosely packed bilayer arrangement at elevated temperatures. At such temperatures, the side-side correlations between the aliphatic and aromatic portions of neighboring mesogens are thermally suppressed and thus do not yield any fine structure (sharp peaks) in the WAXS. There is only a broad peak in WAXS indicative of weak spatial correlations between the mesogens on the 3-5 $\AA$ length scale. On cooling from $150{ }^{\circ} \mathrm{C}$, the $75 \AA$ LC peak first starts to recede at about $110{ }^{\circ} \mathrm{C}$. This decrease in the peak intensity is concurrent with the evolution of the $120 \AA$ peak at $q \sim 0.053 \AA^{-1}$ (and higher orders) between 115 and $105{ }^{\circ} \mathrm{C}$. Additionally, the appearance of this scattering is coincident with a (liquid) crystallization event in the material as marked by the 
a
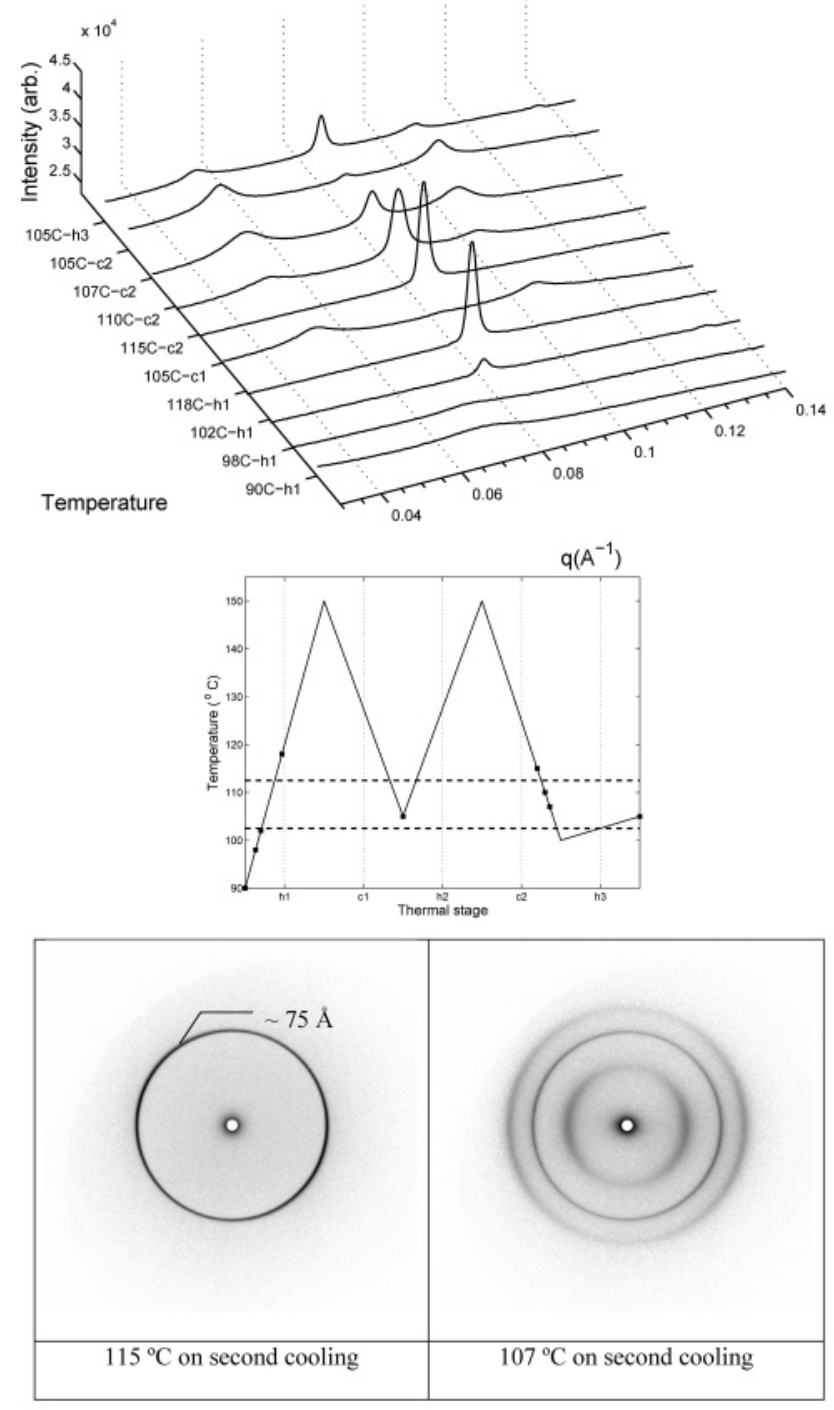

b

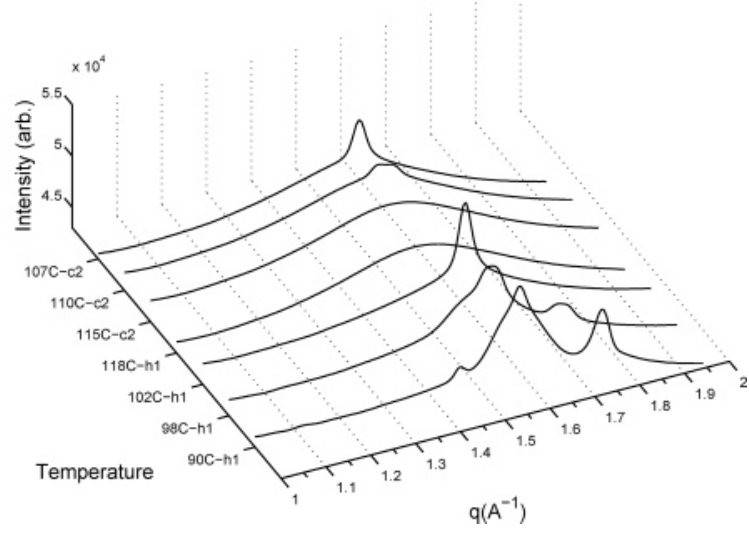

Figure 2. Annotations $\mathrm{h} 1, \mathrm{c} 1, \mathrm{c} 2$, and $\mathrm{h} 3$ refer to data taken during first heating to $150{ }^{\circ} \mathrm{C}$ from room temperature, initial cooling from $150{ }^{\circ} \mathrm{C}$, subsequent cooling from $150{ }^{\circ} \mathrm{C}$, and final heating to $105^{\circ} \mathrm{C}$, respectively. (a) Circularly integrated SAXS data as a function of temperature at select points and representative 2-D data taken at 115 and $107{ }^{\circ} \mathrm{C}$ showing the emergence of the first and second orders of the large length scale layered structure on either side of the $75 \AA$ LC ring. Inset: temperature profile of the experiment. Data are shown for points identified by the black squares ( $\mathbf{\square})$. The dashed lines delineate the approximate existence limits of the $120 \AA$ structure. (b) Circularly integrated WAXS data as a function of temperature at select points. appearance of a sharp peak at $\sim 4 \AA$ in the wide-angle regime, shown in Figure $2 b$. With continued cooling the $120 \AA$ peak disappears as does the $75 \AA$ LC reflection, just below $100^{\circ} \mathrm{C}$. On reheating, the $120 \AA$ peak reappeared at about $105^{\circ} \mathrm{C}$. The sample was held at $105{ }^{\circ} \mathrm{C}$, and the scattering, including the presence of the second-order reflection, was found to be unchanged after $100 \mathrm{~min}$. Finally, on cooling again, the $120 \AA$ peak disappears and the $21 \AA$ peak returns and persists to room temperature. The $120 \AA$ structure was thus formed reversibly on heating and cooling and found to exist over a very small and specific temperature range of approximately $10-15^{\circ} \mathrm{C}$. On the basis of the presence of a second-order peak at $60 \AA$, the structure is presumed to be layerlike. The structure responsible for the $120 \AA$ scattering appears to be an intermediate phase present during the transition from the $75 \AA$ LC mesophase to the $21 \AA$ mesophase.

The specificity and reproducibility of the temperatures at which the structure emerged suggest strongly that the system transitions systematically via this state. The 2-dimensional SAXS patterns from which the curves were derived show that the scattering at $120 \AA$ is qualitatively different than the LC derived scatter at $75 \AA$-the peaks are much more diffuse. There is also some weak mutually parallel orientation in both sets of scattering. Attempts at direct imaging of the structure responsible for the SAXS peak at $120 \AA$ were unsuccessful-samples were rapidly quenched into liquid nitrogen from $105^{\circ} \mathrm{C}$ and inspected by TEM and AFM, but no periodic morphology on the $120 \AA$ length scale could be clearly and conclusively discerned.

The data is unambiguous is its indication of a large length scale microstructure with a small temperature stability window. It can be understood in one context to arise from a microphase separation between differently complexed portions of the poly(acrylic acid) backbone. The situation is analogous to that seen in polysoaps or comb copolymers where there is experimentally observed and theoretically modeled collapse from a coil to a globular state in solutions of hydrophilic polymers which have been modified with hydrophobic side chains. ${ }^{27-29}$ In the globular collapse, hydrophobic side chains aggregate to form a core which is enveloped by the hydrophilic polymer backbone, in essence forming a micelle. Backbone segments form loops at the surface of the micelle and may also bridge them. The dynamics of the process depend on the solvent quality for the backbone and side chains, the length of the side chains, their spacing along the backbone, and the energetics associated with the diffusion required to bring them into contact. Our system consists of a hydrophilic backbone with lipophilic side chains grafted on via hydrogen bonding. It differs in the lack of an explicit solvent and in the mobility of the reversibly hydrogen-bonding side chains along the backbone, subject to some activation barrier, which would allow for dynamic changes of the local graft density, as shown in Figure 3. Finally, apart from the hydrophobic-hydrophobic interactions, there is the enthalpy of (liquid) crystallization that also drives the aggregation of side chains along the backbone and that would encourage the formation of a planar or prolate spheroid rather than an amorphous globule due to the side-side ordered packing of the smectic ordered mesogens. The situation is depicted schematically in Figure 4. The phenomenon observed here is unique in that it occurs in the melt state and, from consideration of the scattering, gives rise to an ordered, layered structure, as opposed to randomly distributed globular aggregates. The concurrence of the onset of order on the 4-5 $\AA$ length scale with the emergence of the large length scale structure underlines the importance of the aggregation of the mesogenic side chains 


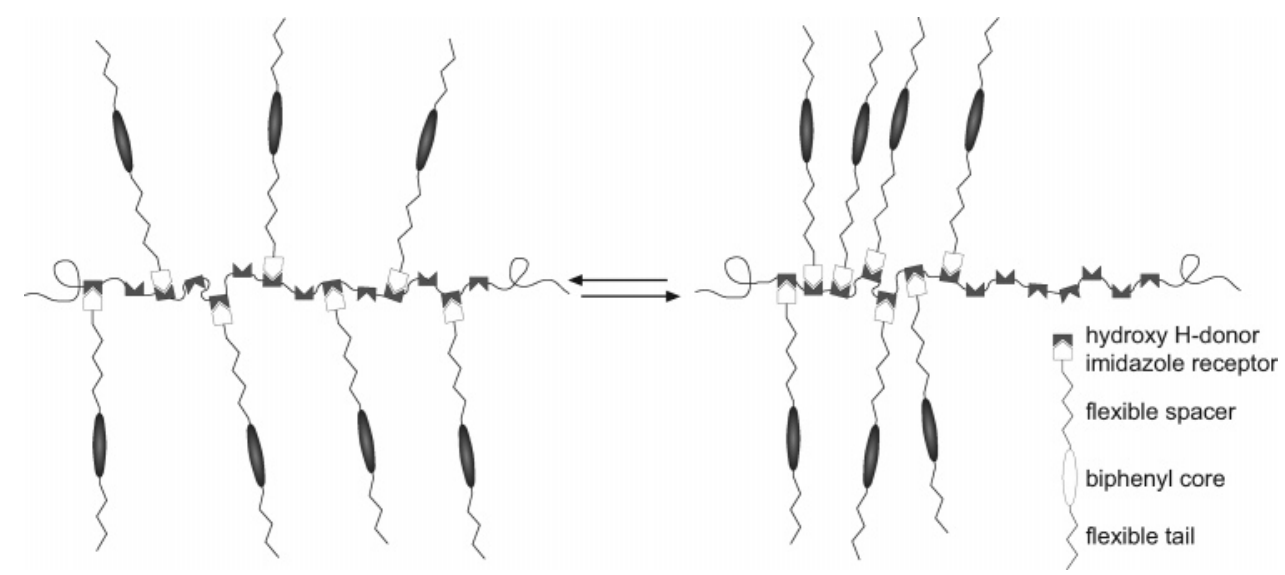

Figure 3. Local graft density is dynamic and can change as mesogens reversibly hydrogen bond at different points along the chain. In the above case, the mesogens go from a homogeneous distribution to sequestering at one end of the chain.

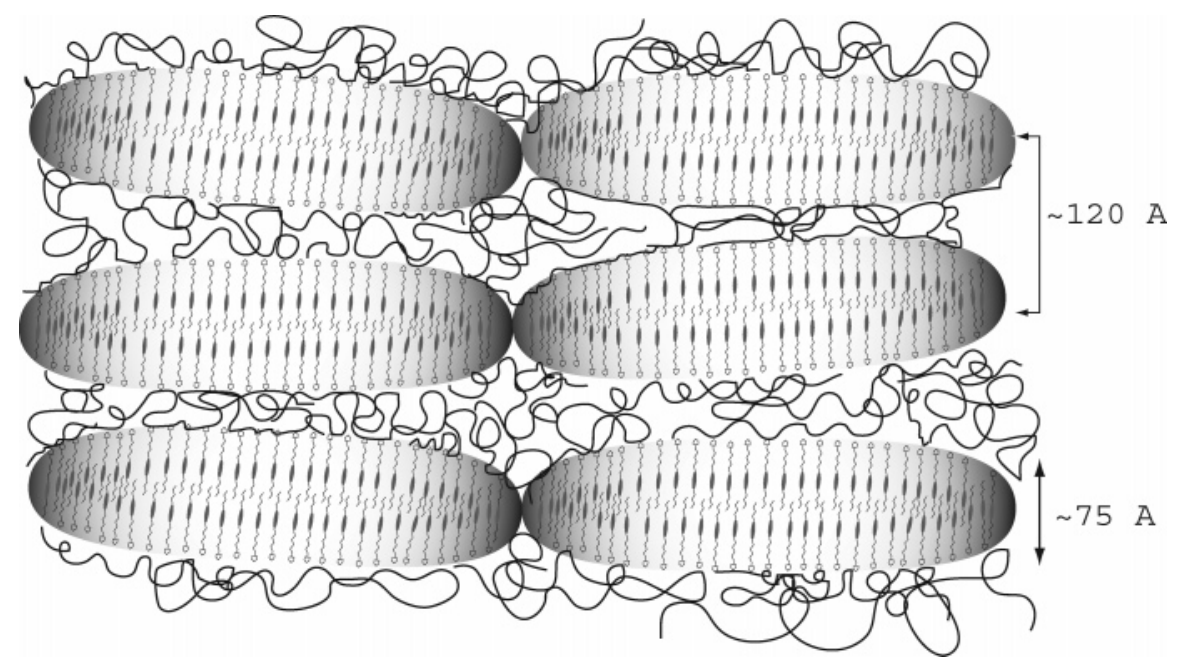

Figure 4. Schematic of possible arrangement of the mesogenic side-chain aggregates at $105{ }^{\circ} \mathrm{C}$ where the $120 \AA$ scattering is well established and the $75 \AA$ signal is nearly extinct. Within the clusters there is a smectic bilayer that is responsible for the very weak/residual $75 \AA$ scatter observed along with the $120 \AA$ layers.

in dictating this phenomenon. Though no explicit solvent is present, the kinetics here are aided by the mesogen itself, which exists in the system in excess of the polymer and acts as a significant plasticizer.

Viewed from a different perspective, one can think of mesogen aggregation along individual chains as leading to the formation of a block comb copolymer with alternating regions of backbone bearing different side-chain densities, poly $(\mathrm{AA})_{m^{-}}$ block-poly(AA-graft-LC) $)_{n}$. Such a system has been considered theoretically ${ }^{30,31}$ and found to display ordering at two length scales dependent on the specification of $m$ and $n$. The length scale of the structure is managed by the interplay among the attractive enthalpy of the mesogenic side chains, $\Delta H_{\text {side chains, }}$ the entropic penalty of the extended conformations of the poly(acrylic acid) backbone when it is complexed, $\Delta S_{\text {backbone, }}$, the entropic penalty due to mesogen localization, $\Delta S_{\text {side chains, }}$, and the enthalpic cost of creating periodic interfaces between dissimilar media, $\sim \chi_{\text {side chains }- \text { backbone. The length scale was found }}$ to be independent of molecular weight-similar dimensions for elevated temperature microphase-separated structures were found for samples prepared with $37.7 \mathrm{~K}$ and $85.5 \mathrm{~K}$ poly(acrylic acid). Thus, the layer repeat distance is prescribed by the average size of the aggregates of $\mathrm{H}$-bonded side chains, with multiple backbones contributing to the formation of each cluster, a situation seen in the microstructuring of poly(urethanes) with a characteristic hard segment domain size. ${ }^{32,33}$
In conclusion, hydrogen bonding was used successfully to produce a side-group liquid crystalline polymer. A rich temperature-dependent phase behavior was observed, including a high-temperature phase which exhibited microphase separation on a length scale well above the size of the mesogen or that achievable through swelling of the smectic layers by the polymer backbone alone. To our knowledge, this represents the first experimental observation of such microphase separation in the melt state. It may be considered either in the context of a coilglobule collapse driven by attractive side-chain interaction or microphase separation on two length scales in a comb copolymer due to liquid crystallization driven side-chain aggregation along the backbone. In either case, critical variables are the graft density and the attractive interaction between side chains. In our system, these two variables are presumed to be strong functions of temperature. Additional studies are required to fully elucidate the mechanism of formation of the observed structures.

Acknowledgment. The authors are indebted to Professor Nily Dan of Drexel University and Professor Y. Cohen of the Technion, Israel, for useful discussions and to Professor B. Hsiao and Dr. F. Yeh of SUNY-Stony Brook for facilitating measurements at beamline X27C at Brookhaven. Funding was provided by the National Science Foundation through Grants DMR ECS-0103297 and NIRT0103297. 


\section{References and Notes}

(1) Hirschberg, J.; Brunsveld, L.; Ramzi, A.; Vekemans, J.; Sijbesma, R. P.; Meijer, E. W. Nature (London) 2000, 407, 167-170.

(2) Sijbesma, R. P.; Meijer, E. W. Curr. Opin. Colloid Interface Sci. 1999, 4, 24-32.

(3) Muthukumar, M.; Ober, C. K.; Thomas, E. L. Science 1997, 277, $1225-1232$.

(4) Lehn, J. M. Science 2002, 295, 2400-2403.

(5) Kato, T.; Frechet, J. M. J. Macromolecules 1989, 22, 3818-3819.

(6) Kato, T.; Kihara, H.; Uryu, T.; Fujishima, A.; Frechet, J. M. J. Macromolecules 1992, 25, 6836-6841.

(7) Kato, T.; Nakano, M.; Moteki, T.; Uryu, T.; Ujiie, S. Macromolecules 1995, 28, 8875-8876.

(8) Kato, T.; Hirota, N.; Fujishima, A.; Frechet, J. M. J. J. Polym. Sci., Part A: Polym. Chem. 1996, 34, 57-62.

(9) Lee, C. M.; Jariwala, C. P.; Griffin, A. C. Polymer 1994, 35, 45504554.

(10) Kihara, H.; Kato, T.; Uryu, T.; Frechet, J. M. J. Liq. Cryst. 1998, $24,413-418$

(11) Bazuin, C. G.; Brandys, F. A.; Eve, T. M.; Plante, M. Macromol. Symp. 1994, 84, 183-196.

(12) Bazuin, C. G.; Brandys, F. A. Chem. Mater. 1992, 4, 970-972.

(13) Fouquey, C.; Lehn, J.-M.; Levelut, A.-M. Adv. Mater. 1990, 2, 254257.

(14) Kato, T.; Frechet, J. M. J.; Wilson, P. G.; Saito, T.; Uryu, T.; Fujishima, A.; Jin, C.; Kaneuchi, F. Chem. Mater. 1993, 5, 10941100.

(15) Kawakami, T.; Kato, T. Macromolecules 1998, 31, 4475-4479.

(16) Kosonen, H.; Ruokolainen, J.; Knaapila, M.; Torkkeli, M.; Serimaa, R.; Bras, W.; Monkman, A. P.; ten Brinke, G.; Ikkala, O. Synth. Met. 2001, 121, 1277-1278.

(17) Kosonen, H.; Ruokolainen, J.; Knaapila, M.; Torkkeli, M.; Jokela, K.; Serimaa, R.; ten Brinke, G.; Bras, W.; Monkman, A. P.; Ikkala, O. Macromolecules 2000, 33, 8671-8675.
(18) Ikkala, O.; Ruokolainen, J.; ten Brinke, G. Abstr. Pap. Am. Chem Soc. 1999, 217, 184-POLY

(19) Ruokolainen, J.; Saariaho, M.; Ikkala, O.; ten Brinke, G.; Thomas, E. L.; Torkkeli, M.; Serimaa, R. Macromolecules 1999, 32, 11521158.

(20) TenBrinke, G.; Ruokolainen, J.; Ikkala, O. Europhys. Lett. 1996, 35, 91-95.

(21) Ruokolainen, J.; Torkkeli, M.; Serimaa, R.; Vahvaselka, S.; Saariaho, M.; tenBrinke, G.; Ikkala, O. Macromolecules 1996, 29, 6621-6628.

(22) Ruokolainen, J.; Tanner, J.; Tenbrinke, G.; Ikkala, O.; Torkkeli, M.; Serimaa, R. Macromolecules 1995, 28, 7779-7784.

(23) Ikkala, O.; Ruokolainen, J.; Tenbrinke, G.; Torkkeli, M.; Serimaa, R. Macromolecules 1995, 28, 7088-7094.

(24) Makinen, R.; Ruokolainen, J.; Ikkala, O.; de Moel, K.; ten Brinke, G.; De Odorico, W.; Stamm, M. Macromolecules 2000, 33, 34413446.

(25) Osuji, C.; Chao, C. Y.; Bita, I.; Ober, C. K.; Thomas, E. L. Adv. Funct. Mater. 2002, 12, 753-758.

(26) Chao, C. Y.; Li, X. F.; Ober, C. K.; Osuji, C.; Thomas, E. L. Adv Funct. Mater. 2004, 14, 364-370.

(27) Vasilevskaya, V. V.; Klochkov, A. A.; Khalatur, P. G.; Khokhlov, A. R.; ten Brinke, G. Macromol. Theory Simul. 2001, 10, 389-394.

(28) Philippova, O. E.; Andreeva, A. S.; Khokhlov, A. R.; Islamov, A. K.; Kuklin, A. I.; Gordeliy, V. I. Langmuir 2003, 19, 7240-7248.

(29) Lee, N. K.; Abrams, C. F. J. Chem. Phys. 2004, 121, 7484-7493.

(30) Nap, R. J.; ten Brinke, T. Macromolecules 2002, 35, 952-959.

(31) Nap, R. J.; Kok, C.; ten Brinke, G.; Kuchanov, S. I. Eur. Phys. J. E 2001, 4, 515-519.

(32) Eisenbach, C. D.; Heinemann, T.; Ribbe, A.; Stadler, E. Angew. Makromol. Chem. 1992, 202, 221-241.

(33) Tyagi, D.; Wilkes, G. L.; Lee, B.; McGrath, J. E. In Advances in Elastomers and Rubber Elasticity; Mark, J., Ed.; Plenum Press: New York, 1988.

MA052547+ 